\title{
Uncertainty analysis of computational methods for deriving sensible heat flux values from scintillometer measurements
}

\author{
P. A. Solignac, A. Brut, J.-L. Selves, J.-P. Béteille, J.-P. Gastellu-Etchegorry, P. Keravec, P. Béziat, and E. Ceschia \\ CESBIO, 18, avenue Edouard Belin, bpi 2801, 31401 Toulouse Cedex 9, France
}

Received: 8 April 2009 - Published in Atmos. Meas. Tech. Discuss.: 5 June 2009

Revised: 14 September 2009 - Accepted: 3 November 2009 - Published: 18 November 2009

\begin{abstract}
The use of scintillometers to determine sensible heat fluxes is now common in studies of land-atmosphere interactions. The main interest in these instruments is due to their ability to quantify energy distributions at the landscape scale, as they can calculate sensible heat flux values over long distances, in contrast to Eddy Covariance systems. However, scintillometer data do not provide a direct measure of sensible heat flux, but require additional data, such as the Bowen ratio $(\beta)$, to provide flux values. The Bowen ratio can either be measured using Eddy Covariance systems or derived from the energy balance closure. In this work, specific requirements for estimating energy fluxes using a scintillometer were analyzed, as well as the accuracy of two flux calculation methods. We first focused on the classical method (used in standard softwares) and we analysed the impact of the Bowen ratio on flux value and uncertainty. For instance, an averaged Bowen ratio $(\beta)$ of less than 1 proved to be a significant source of measurement uncertainty. An alternative method, called the " $\beta$-closure method", for which the Bowen ratio measurement is not necessary, was also tested. In this case, it was observed that even for low $\beta$ values, flux uncertainties were reduced and scintillometer data were well correlated with the Eddy Covariance results. Besides, both methods should tend to the same results, but the second one slightly underestimates $H$ while $\beta$ decreases $(<5 \%)$.
\end{abstract}

\section{Introduction}

In order to better understand biosphere-atmosphere interactions, scientists require improved tools to accurately estimate exchanges of mass and energy at the land-atmosphere interface. Indeed, these fluxes represent the boundary conditions

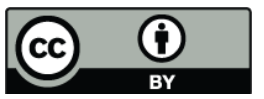

Correspondence to: P. A. Solignac (pasolignac@gmail.com) for studies dedicated to both continental surfaces and atmospheric processes. Currently, various techniques for surface flux measurements are used, including both local methods (Dugas et al.,1991; Dabberdt et al., 1993) and path-averaged ones (Meijninger, 2003). Furthermore, the emergence of remote sensing techniques (Bastiaanssen et al., 1998) leads to a need for in situ flux estimation integrated over the average pixel size of satellite images for complementary information. Scintillometry is a ground-based technique that represents one of the few methods capable of providing information integrated over large areas; it allows for measurement of sensible heat fluxes on length scales ranging from a few hundred meters to a few kilometres.

Scintillometers measure the structure parameter of refractive index $\left(C_{n^{2}}\right)$, which characterises turbulence intensity within the atmosphere (Ochs and Wilson, 1993). By using the Monin-Obukhov Similarity Theory (MOST) and complementary parameters (meteorological conditions and site features such as vegetation height), $C_{n^{2}}$ can be directly related to sensible heat flux. However, these additional parameters increase the sources of flux uncertainty. In a study over a complex sloping terrain, Hartogensis et al. (2003) estimated the respective contributions of each complementary measurement to the final error in the sensible flux. They concluded that the effective height of the scintillometer was most important (64\%), followed by the transect length (14\%) and the Bowen ratio $(8 \%)$. The choice of the universal function $f_{T}$ (see Eq. 5), following the Monin-Obukhov similarity theory, can also be a large source of error; for instance, the relative difference between the parameterisation of de Bruin et al. (1993) and Andreas (1988) can reach 16\% (Meijninger et al., 2004).

The first step in the classical calculation of the sensible heat flux by scintillometry is to convert $C_{n^{2}}$ to $C_{T^{2}}$ (the structure parameter of temperature) by introducing a temperature/humidity correlation factor, hereafter referred to as the Bowen ratio, $\beta$. The Bowen ratio is defined as the ratio of

Published by Copernicus Publications on behalf of the European Geosciences Union. 
sensible heat flux (hereafter $H)$ to latent heat flux $\left(L_{v} E\right)$. The factor $\beta$ can be neglected in the case of large $\beta$ values as its contribution is weak (de Bruin et al., 1995). However, it has a large impact on the accuracy of $C_{T^{2}}$, and therefore on the sensible heat flux estimation in the case of strong humidity conditions (when $\beta<1$, Green and Hayashi, 1998; Moene et al., 2005). During a measurement campaign in Turkey, Meijninger and de Bruin (2000) calculated $H$ without any turbulent data from Eddy Covariance system and showed that taking $\beta=1$ instead of $\beta=0.3$ leads to a $15 \%$ error in $H$. The sensitivity of $H$ to $\beta$ values is even more important when $\beta<0.3$, and as $H$ is weak, it is even more difficult to get a better accuracy on $H$ due to measurement uncertainties in $\beta$, which can be quite large. By comparing different Eddy Covariance data sets, Twine et al. (2000) found a $\beta$ standard deviation of 0.18 for a range of $\beta$-values varying from 0.1 to 2 . Konzelmann et al. (1997) reported $\beta$ values of $0.4 \pm 0.1$ during a campaign in Switzerland dedicated to the study of evaporation in the mountains. Eventually, Hartogensis et al. (2003) assumed a 50\% error in the Bowen ratio when calculating the respective contributions of each parameter to the flux error.

Green and Ayashi (1998) proposed an alternative method that does not require $\beta$ as an input parameter. They calculated sensible heat flux $(H)$ assuming a closed energy budget and using an iterative process. This method is called the " $\beta$ closure method" (BCM), according to Twine et al. (2000). Hoedjes et al. (2002) used it in Northwestern Mexico and obtained good results over irrigated cropland. With this method, Marx et al. (2008) calculated the sensible heat flux over two different surfaces, as well as the associated uncertainties caused by the inclusion of additional parameters in the computation algorithm. They found flux uncertainties of roughly $7 \%$ and $8 \%$, respectively.

The main objective of this work is to make a direct comparison of two different algorithms for computing sensible heat flux from scintillometer data and to comment on their robustness. We chose to evaluate the impact of the $\beta$ value on the accuracy of sensible heat flux computations, and analysed the advantages and drawbacks of each algorithm for the $H$-flux computation. The results are presented with the related measurement uncertainty so as to show the reliability of each computational method. The final purpose of this work is to advise one of both methods, regarding the instrumental set-up and the measurement uncertainties. With these objectives, we used the 2007 flux data set measured with a scintillometer and an EC system at one of the CESBIO experimental sites. This approach was also used to survey Bowen ratio evolution and to focus on three different periods of the year corresponding to various ranges of $\beta$ values.

After presenting the flux calculation theory with scintillometry, we describe the two algorithms for flux computation. First, the features of the classical method are discussed. Then, the " $\beta$-closure method" is presented, along with a detailed analysis of its robustness. Finally, values of sensible heat flux calculated by both methods and by EC stations are compared. Optimum conditions for the use of each method are determined, as are the relative errors associated with the scintillometry measurements.

\section{Theory}

\subsection{Theory of wave propagation for scintillometers}

Time variation of the refractive index $(n)$ of air characterises turbulent air motions within the atmosphere, and is known to be closely related to temperature and humidity fluctuations. To describe the turbulent fluctuations of the atmosphere, we can use the structure coefficient of refractive index, $C_{n^{2}}$ which is defined as

$C_{n^{2}}=\frac{\overline{[n(x+r)-n(x)}^{2}}{r^{\frac{2}{3}}}$,

where $x$ is the measurement position of the air refractive index $n$ and $r$ is the distance between two measurement points.

A scintillometer is composed of a transmitter that emits a light beam and a receiver. The receiver measures fluctuations (or scintillations) in the beam intensity along its path through the atmosphere. The relationship between $C_{n^{2}}$ and the propagation statistics of the electromagnetic radiation $\left(\sigma_{\ln I}^{2}\right.$, measured at the scintillometer receiver) is given by (2) (Wang et al., 1978).

$C_{n^{2}}=1.12 * \sigma_{\mathrm{lnI}}^{2} * D^{\frac{7}{3}} * L^{-3}$

In the above equation, $L$ is the optical path length (or transect); $D$ is the diameter of the beam and $\sigma_{\ln I}^{2}$ is the variance of the natural-log of intensity fluctuations. $C_{n^{2}}$ is the output variable of the scintillometer, as Eq. (2) is processed by the instrument electronics. Over the entire electromagnetic spectrum, from visible to microwave wavelengths, values of $C_{n^{2}}$ depend only upon absolute temperature $(T)$, absolute humidity $(Q)$ and atmospheric pressure $(P)$. Usually, the influence of pressure is neglected and $C_{n^{2}}$ is expressed as a function of the structure parameter of temperature and humidity, $\left(C_{T^{2}}\right)$ and $\left(C_{Q^{2}}\right)$, respectively (Hill et al., 1980),

$C_{n^{2}}=\frac{A_{T}^{2}}{\bar{T}^{2}} C_{T^{2}}+\frac{A_{Q}^{2}}{\bar{Q}^{2}} C_{Q^{2}}+2 \frac{A_{T} A_{Q}}{\overline{T Q}} C_{T Q}$

The variables $A_{T}$ and $A_{Q}$ depend on the wavelength of the light beam, the absolute temperature and the humidity, according to Andreas (1989). 


\subsection{Sensible heat flux derived from an optical scintillometer}

An optical scintillometer is more sensitive to variations of temperature than humidity, since the light emitted by the transmitter is in the near infrared. Assuming a temperature/humidity cross-correlation equal to unity $\left(\left|R_{T q}\right| \approx 1\right)$, Eq. (3) can be simplified to express the refractive index as a function of $C_{T^{2}}$ and $\beta$ (Wesely, 1976):

$C_{n^{2}} \approx\left(\frac{-0.78 * 10^{-6} * P}{T^{2}}\right)^{2} C_{T^{2}}\left(1+\frac{0.03}{\beta}\right)^{2}$

with $T$, the absolute temperature (K), and $P$, the atmospheric pressure $(\mathrm{Pa})$. In this case, the sensible heat flux $(H)$ can be derived from the structure parameter of temperature $\left(C_{T^{2}}\right)$ according to the Monin-Obukhov Similarity Theory (Hill, $1989)$, with a universal function $\left(f_{T}\right)$ that depends on the atmospheric stability $\left(z / L_{O}\right)$.

$C_{T^{2}}=T_{*}^{2} z^{-2 / 3} f_{T}\left(z / L_{O}\right)$

where, $L_{O}$ is the Obukhov length and $T_{*}$, the temperature scale. As the universal function $f_{T}$ is parameterised from experimental data, many additional empirical expressions have been proposed (Wyngaard et al., 1971; Hill et al., 1992). For this study, we opted for the parameterisation proposed by Andreas (1988).

For unstable conditions (i.e., $L_{O}<0$ )

$\frac{C_{T^{2}}\left(z_{\mathrm{LAS}}-d\right)^{\frac{2}{3}}}{T_{*}^{2}}=4.9\left(1-6.1 \frac{z_{\mathrm{LAS}}-d}{L_{O}}\right)^{-\frac{2}{3}}$

where $z_{\text {LAS }}$ the height of the scintillometer and $d$ is the displacement height. Both the displacement height and the roughness length $\left(z_{0}\right)$ are directly obtained by a measurement of the vegetation height, $h_{\mathrm{veg}}$. These terms are roughly equal to $0.6 h_{\mathrm{veg}}$ and $0.1 h_{\mathrm{veg}}$, respectively. The Obukhov length $L_{O}$ is expressed by

$L_{O}=\frac{u_{*}^{2} T}{g k_{v} T_{*}}$

where $u_{*}$ is the friction velocity. This latter can either be taken from turbulent data of the Eddy Covariance system or calculated via the stability function $\psi_{m}\left(z / L_{O}\right)$ given by Panofsky and Dutton (1984):

$u_{*}=\frac{k_{v} u}{\ln \left(\frac{z_{u}-d}{z_{0}}\right)-\psi_{m}\left(\frac{z_{u}-d}{L_{O}}\right)+\psi_{m}\left(\frac{z_{0}}{L_{O}}\right)}$

$k_{v}$ is the Von Karman constant, $z_{0}$ is the roughness length and $u$ is the wind speed at the measurement height. $\psi_{m}$ is an universal function of stability (Businger et al., 1967; Paulson, 1970), which is defined under unstable atmospheric conditions as:

$\psi_{m}\left(\frac{z}{L_{O}}\right)=2 \ln \left[\frac{1+x}{2}\right]+\ln \left[\frac{1+x^{2}}{2}\right]-2 \arctan (x)+\frac{\pi}{2}$ with

$x=\left(1-\frac{16 z}{L_{O}}\right)^{\frac{1}{4}}$

Eventually, $H_{\mathrm{LAS}}$ can be derived from the parameters

$H_{\mathrm{LAS}}=-\rho c_{p} T_{*} u_{*}$

where $c_{p}$ is the specific heat of air at constant pressure, and $\rho$ is the density of air.

In this paper, we used two different computation methods, but steps (4) through (11) were performed identically in both methods. The primary difference between methods was in the determination of the Bowen ratio $(\beta)$. The first algorithm, referred to here as the "classical method", was derived from the WINLAS v.1 software package, provided by Kipp and Zonen, and was an iterative procedure combining Eqs. (6), (7) and (8). The second algorithm, here referred to as the " $\beta$-closure method" (BCM) was first used by Green and Ayashi (1998), and a brief description can be found in Meijninger et al. (2002a). In this method, $H_{\mathrm{LAS}}$ is calculated by closing the energy budget (Eq. 12):

$R_{N}-G-S-\varepsilon=L_{v} E+H$

where $R_{N}$ is net radiation, $G$ is the soil heat storage, $L_{v} E$ is the latent heat flux and $S$ is the gathering of heat flux storages in the canopy, and under the mast. $\varepsilon$ is the energy used for photosynthesis, and is usually small enough that it can be neglected (Lamaud et al., 2001).

A detailed description of each computational process, with the associated uncertainty analysis, is provided below.

\section{Experimental}

This study was conducted in Lamasquère, France $\left(43^{\circ} 29^{\prime} 36^{\prime \prime} \mathrm{N} ; \quad 1^{\circ} 14^{\prime} 14^{\prime \prime} \mathrm{E} ; \quad\right.$ altitude $\left.180 \mathrm{~m}\right), \quad 40 \mathrm{~km}$ west of the city of Toulouse. The work was part of the "Sud-Ouest" project, coordinated by CESBIO (http://www.cesbio.ups-tlse.fr/fr/sud_ouest.html), which is dedicated to understanding the effects of climate on regional ecosystems. The project's objectives are to diagnose the ecosystem's behaviour through the use of monitoring instruments and accurate modelling, and to simulate possible ecosystem evolution scenarios according to various land use patterns. The site observed in this study was a flat, homogeneous field upon which wheat was grown during the year 2007 (cf. Fig. 1). A Large Aperture Scintillometer (LAS) that was designed and built at CESBIO by the GRITE team (Groupement de Recherche en Instrumentation et Techniques Environnementales) was installed in this field. Its aperture size $(D)$ is $0.203 \mathrm{~m}$ and the wavelength of the light beam emitted by the transmitter is $940 \mathrm{~nm}$. An optical band pass filter at approximately $940 \mathrm{~nm}$ is added to cut off all visible wavelengths. This scintillometer was positioned 
a)

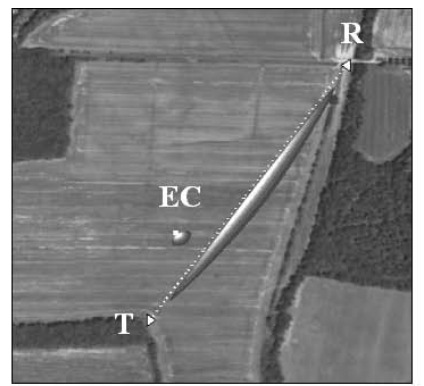

b)

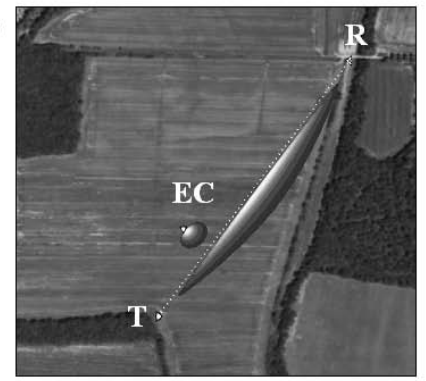

c)

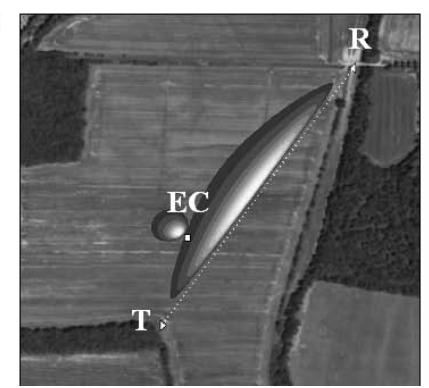

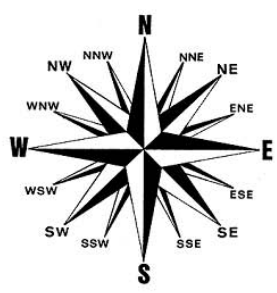

$300 \mathrm{~m}$

\section{FOOTPRINTS :}

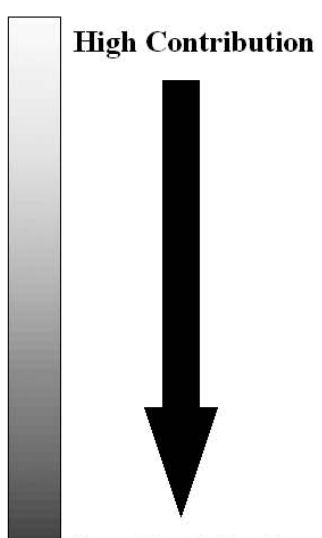

Low Contribution

Fig. 1. Study area of Lamasquère. Location of the Eddy Covariance system (EC) with the scintillometer transmitter $(T)$ and receiver $(R)$. Footprints are displayed for the three periods: (a) P1 (April), (b) P2 (June) and (c) P3 (September).

on a stable $3 \mathrm{~m}$-high concrete tower built to avoid instrument oscillations due to strong wind. The path length between the transmitter and the receiver was approximately $567 \mathrm{~m}$. The output signal, expressed as a voltage, was recorded by a low-power consumption computer at $1 \mathrm{kHz}$, and was filtered for absorption phenomena at $0.1 \mathrm{~Hz}$ (Meijninger et al., 2002b). $C_{n^{2}}$ was calculated according to Eq. (2). A brief preliminary comparison of the CESBIO-built instrument to another LAS (METAIR group from Wageningen University and Research Center) was performed and provided a good correlation between the results of the two instruments.

During the intercomparison, the heights of both scintillometers were different, $z_{\mathrm{LAS}}=6 \mathrm{~m}$ for the METAIR LAS and $z_{\text {LAS }}=3 \mathrm{~m}$ for the CESBIO LAS, but this height difference was accounted for in calculation of the sensible heat flux $(H)$. Data from both scintillometers were found to be linearly related: $H_{\text {LAS_CESBIO }}=1.28 * H_{\text {LAS_METAIR }}\left(R^{2}=0.981\right)$. The coefficient (1.28) was found to be consistent across a number of measurements, and was attributed to the greater sensitiv-

ity of the GRITE scintillometer to the focus of the detector and the effective diameter of the light beam (a misalignment of the instruments can reduce the effective diameter of the beam observed at the receiver). This phenomenon has been previously reported in other comparisons of multiple scintillometers, with relative differences ranged from 5\% (Meijninger et al., 2002a) to $21 \%$ (Kleissl et al., 2008). Since our scintillometer was in the development stage when this work was conducted, a calibration campaign was conducted prior to each measurement period, to avoid flux overestimation due to misalignment. In addition, a threshold was imposed on the signal amplitude so as to avoid dew effects on scintillometer measurements. Hereafter, the flux $H$ estimated with the scintillometer will be referred to as $H_{\text {LAS }}$.

An eddy covariance system was installed at mid-transect of the scintillometer light beam at a $3.65 \mathrm{~m}$ height. The EC system was equipped with a CSAT3 sonic anemometer (Campbell Scientific Ltd.) to measure wind speed fluctuations in three dimensions, as well as sonic temperature, and an IR gas analyzer Licor 7500 (Campbell Scientific Ltd.) was used to measure $\mathrm{H}_{2} \mathrm{O}$ and $\mathrm{CO}_{2}$ concentrations. Typical meteorological sensors were also added to the EC mast to provide mean values for atmospheric pressure, air temperature and relative humidity. The net radiation $\left(R_{N}\right)$ was measured using a CNR1 (Campbell Scientific). Soil heat flux $(G)$ was measured at a depth of $5 \mathrm{~cm}$ using three heat flux plates (hpf01, Hukseflux), and was corrected to consider the storage between the surface and the heat flux plate. All fluxes were averaged over 30-min periods, which provided a good trade-off between eddy sampling and the stationary assumption. Some corrections were applied to the EC system flux estimates, according to the recommendations of the CarboEurope experimental program (Aubinet et al., 2000, 2003; Lee et al., 2004). Thus, wind speed measurements were corrected for double rotation, as advised for crop and grasslands sites. Corrections also accounted for the time lag between the sonic anemometer and the analyser data logger, and high frequency spectral losses, as well as humidity effects, addressed via the WPL correction (Webb et al., 1980).

As the scintillometer location is close to the forest, footprint analyses have been performed using the model of Meijninger et al. (2002). The footprint analyses were conducted for the main wind directions during the selected periods and required values of $L_{O}, u_{*}, \sigma_{v}$ calculated with the Eddy covariance set-up. As the scintillometer height above the canopy is low, the fetch of the footprint is thin, and is always included in the field limits (Fig. 1). In addition, footprints for the turbulent fluxes of the Eddy Covariance system have been calculated using the model of Horst and Weil (1972). These footprints are even more confined in the field. Thus, the field is rather homogeneous (a bit less during the growing season) so according to the footprint analysis, both flux measurements (scintillometer or EC) can be considered as representative of the same area. 
In order to ascertain whether $C_{T^{2}}$ behaviour followed the MOST, observed values of $C_{T^{2}}\left(\mathrm{z}_{\mathrm{LAS}}-d\right)^{2 / 3} / T *^{2}$ were plotted against observed values of $\left(z_{\text {LAS }}-d\right) / L_{O}$ on Fig. 2 for the entire dataset. The universal function proposed by Hill (1992) and de Bruin (1993) were also plotted on the figure, and fit well with previous results, although a slight underestimation was observed. Values of $T_{*}$ and $L_{O}$ were taken from the EC set-up (Hoedjes et al., 2007), while values of $C_{T}^{2}\left(z_{\text {LAS }}-d\right)^{2 / 3} / T *^{2}$ that diverged from Monin-Obukhov theoretical behaviour were rejected. Rejection criteria had a significant influence on results as they resulted in the exclusion of approximately $20 \%$ of the data.

\subsection{Seasonal evolution of the Bowen ratio}

Using Eq. (4), the Bowen ratio $(\beta)$ is required to compute sensible heat flux from scintillometer measurements. In this study, $\beta$ is estimated through the EC turbulent fluxes $H_{\mathrm{EC}}$ and $L_{v} E_{\mathrm{EC}}$. In order to improve the significance of the scintillometer measurements, which rely on $\beta$, and to limit artefacts due to EC measurements, severe criteria were used to eliminate non-relevant $\beta$ values. Specifically, large uncertainties in the Bowen ratio are known to arise from variations in the turbulent fluxes measured by EC systems (mainly due to variations in latent heat flux $L_{v} E_{\mathrm{EC}}$ ). A threshold on flux values has been imposed to reject low flux : $7 \mathrm{~W} / \mathrm{m}^{2}$ for the sensible heat flux and $15 \mathrm{~W} / \mathrm{m}^{2}$ for the latent heat flux (Billesbach et al., 2004). Data were also rejected from night time or thermally stable measurement periods, when LAS data might be affected by the accumulation of dew or water vapour.

Figure 3 shows mean daily $\beta$ values derived from EC data for the period from 1 January 2007 to 1 October 2007. Since the Bowen ratio is closely related to vegetation transpiration capacity, and therefore to vegetation phenology, Leaf Area Index (LAI: leaf surface area per unit of soil surface area), representing the relative surface area of transpiring leaves, was also plotted. Three specific sub-periods were identified over the study period that appeared to correspond to different vegetation life stages (see Fig. 3).

The first period studied was at the end of April (DoY 109 to 114), corresponding to the maximum measured LAI, which was approximately 3.5 , and varied rapidly. The Bowen ratio was low for this period $(\beta \approx 0.1)$, due to high transpiration rates from the vegetation $\left(h_{\mathrm{veg}}=>0.6 \mathrm{~m}\right)$. The second period occurred in midJune (DoY 163 to 169), when vegetation became senescent; green LAI was close to 0 (as was the transpiration rate), but vegetation height reached its maximum $\left(h_{\mathrm{veg}}=0.9 \mathrm{~m}\right)$ and the Bowen ratio reached the value $\beta=1$. The third period occurred at the beginning of September (DoY 248 to 254). Crops were harvested at this time, and the field was nearly completely covered by crop residue (resulting in low vegetation height: $h_{\text {veg }} \approx 0.15 \mathrm{~m}$ ). Sensible heat flux predominated during this period, resulting in a high Bowen ratio $(\beta \approx 2.8)$.

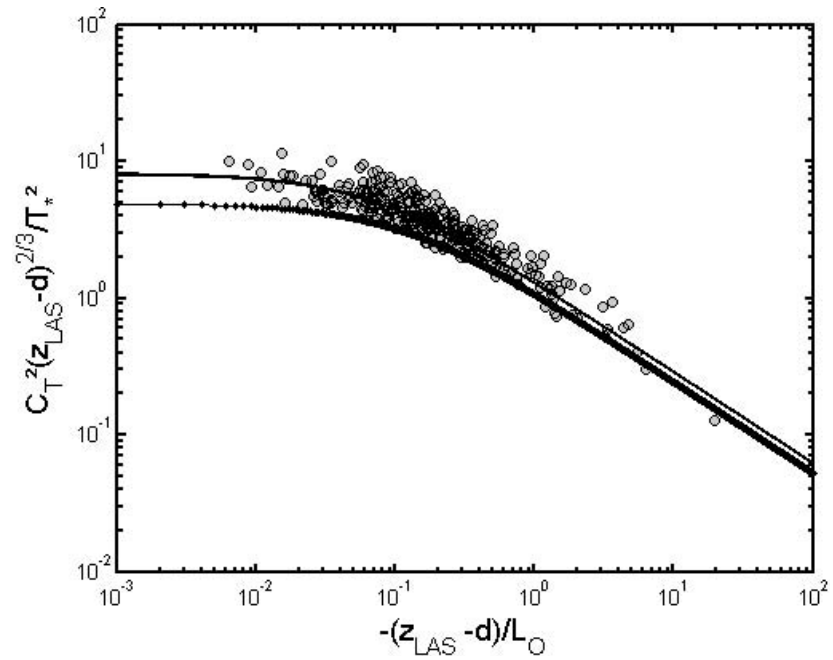

Fig. 2. Observed values of $C_{T^{2}}\left(z_{\mathrm{LAS}}-d\right)^{2 / 3} / T *^{2}$ plotted against observed $\left(z_{\mathrm{LAS}}-d\right) / L_{O}$ during the 3 periods. Data that diverges from MOST behavior are rejected. Solid line represents the scaling of the universal function given by Hill (1992) and dotted line represents the one by de Bruin (1993).

\subsection{Comparison of the "classical" and " $\beta$-closure methods"}

In this section, the two methods for computing the sensible heat flux are described. The various input and output parameters of both methods are summarised in Table 1. All experimental input values are measured by the Eddy Covariance set-up, except for $C_{n^{2}}$ (scintillometer) and various heights $\left(d, z_{0}, z_{\mathrm{EC}}, z_{\mathrm{LAS}}\right)$. Besides, output parameters are calculated by iterative procedures.

\subsubsection{Classical method}

Sensible heat flux ( $\left.H_{\text {LAS }}\right)$ computation using the classical iterative method (WinLAS v.1 software) is described in Fig. 4. A first guess of the Obukhov length is required to initialise the calculation algorithm. The structure parameter of temperature $\left(C_{T^{2}}\right)$ is first calculated from scintillometer signal and using the meteorological data and the Bowen ratio. This coefficient allows the calculation of the temperature scale of the Monin-Obukhov similarity theory (MOST) $T_{*}$ and the friction velocity $u_{*}$ with this first value of $L_{O}$. This latter term is then recalculated using the new values of $T_{*}$ and $u_{*}$. When the algorithm for $L_{O}$ has converged, $T_{*}$ and $u_{*}$ are calculated again, and $H_{\text {LAS }}$ can then be deduced using Eq. (11).

In the classical method, $\beta$ is an input parameter estimated by independent measurements of $H$ and $L_{v} E$ (they are usually provided by EC station or gradient flux systems). Thus, uncertainties in $\beta$ are due to instrumental errors in the flux values. In our case, $\beta$ is derived from measurements of the Eddy Covariance set-up so $\beta=H_{\mathrm{EC}} / L_{v} E_{\mathrm{EC}}$. Random errors in $H_{\mathrm{EC}}$ and $L_{v} E_{\mathrm{EC}}$ flux 


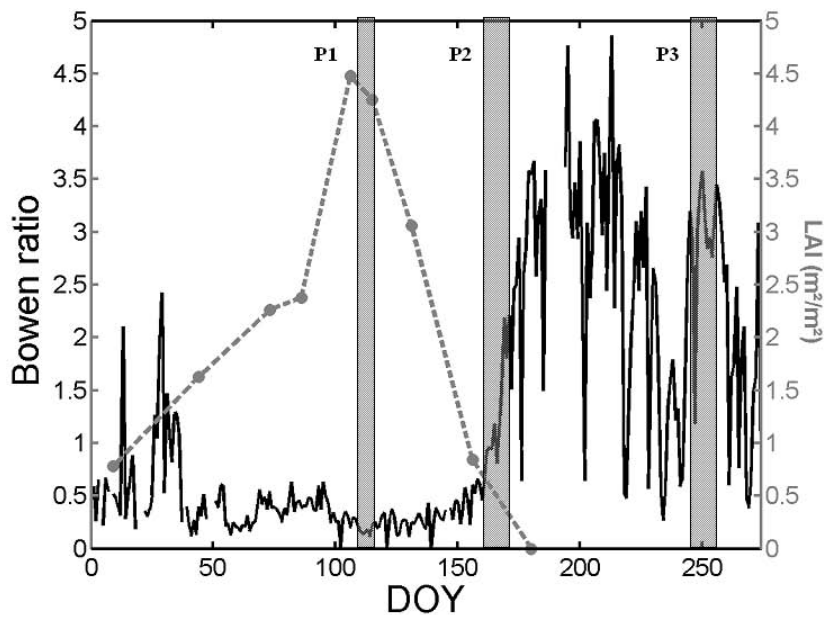

Fig. 3. Leaf Area Index $\left(\mathrm{m}^{2} / \mathrm{m}^{2}\right)$ and mean daily values of the Bowen ratio according to the Day of Year (DoY) in 2007. The three periods are represented by grey boxes: P1 corresponds to Avril dataset (DOY 109 to 114), P2 to June one (DOY 163 to 169) and P3 to September one (DOY 248-254).

have been estimated using a 5-year dataset of EC measurements. The method used was reported by Hollinger and Richardson (2005), who developed a methodology using daily differenced measurements with equivalent environmental conditions. Random errors in the flux calculated using our EC station data were $\sigma_{\mathrm{LVE}}=0.134 L_{v} E+5.8, R^{2}=86.5 \%$ and $\sigma_{H}=0.117 H+6.8, R^{2}=76.4 \%$. Finally, the random error law for the Bowen ratio can be estimated for the same dataset, according to Gaussian error propagation: $\sigma_{\beta}=0.301 \beta+0.02$.

According to Fig. 4, the friction velocity $u_{*}$ is calculated iteratively using a profile approach (Eq. 8). However, $u_{*}$ could be estimated from turbulent data of the EC set-up. Asanuma et al. (2007) investigated the calculation of sensible heat flux from sintillometer measurements on a homogeneous to heterogeneous surfaces using values of $u_{*}$ provided by the EC system, and concluded that the sensitivity of $H_{\text {LAS }}$ to $u_{*}$ depends primarily on the stability index $\left(z / L_{O}\right)$ and on the differences between the scintillometer and EC system footprints. As the error can be large, iterations on $L_{O}$ and $u_{*}$, using the Eqs. (7) and (8), are rather advised for calculating $H_{\text {LAS. }}$ This point is further discussed with the experimental results.

\subsection{2 " $\beta$-closure method"}

In this method, we assume that the Bowen ratio has been correctly measured, and that the energy budget can be balanced by redistributing the closure error across both fluxes (Foken, 2008). Using this assumption, $\beta$ can be expressed as (Bowen, 1926) :

$\beta=\frac{H_{\mathrm{LAS}}}{R_{N}-G-S-H_{\mathrm{LAS}}}$.

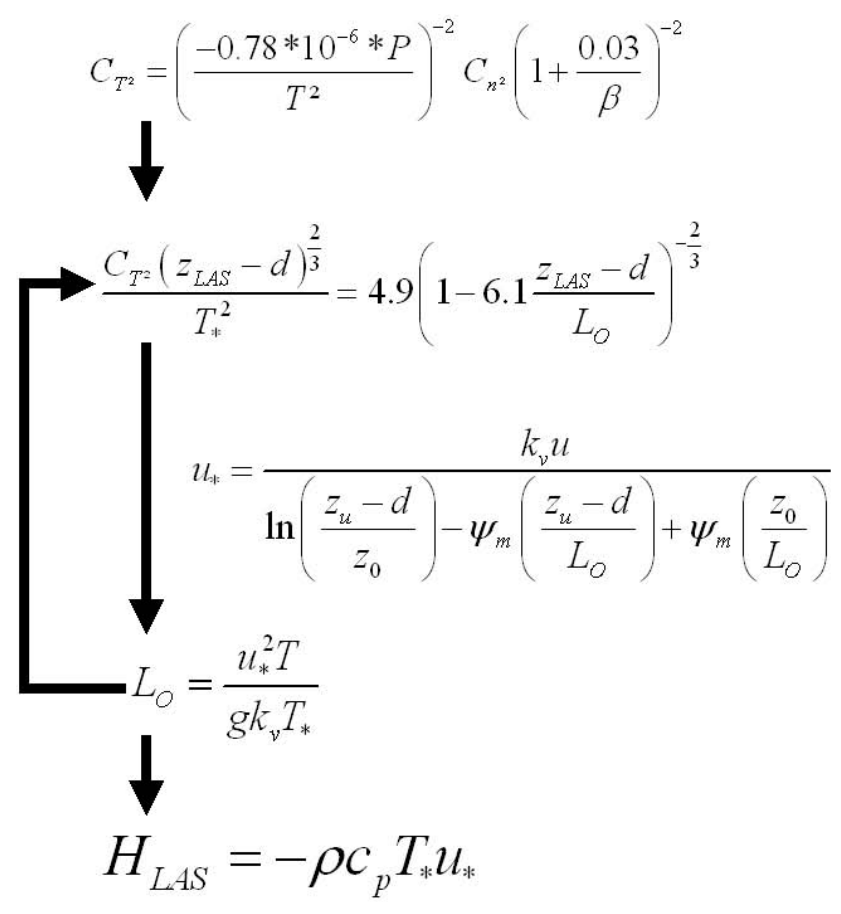

Fig. 4. Schematic description of the classical method process.

Table 1. Input and output parameters that are required for the classical and " $\beta$-closure methods".

\begin{tabular}{lll}
\hline & Input parameters & Output parameters \\
\hline Classical method & $C_{n}{ }^{2}, T, u, P, z_{0}, d, z_{\mathrm{LAS}}$, & $H, L_{O}, T_{*}, u_{*}$ \\
& $z_{\mathrm{EC}}, \beta$ & \\
" $\beta$-closure method” $(\mathrm{BCM})$ & $C_{n}{ }^{2}, T, u, P, z_{0}, d, z_{\mathrm{LAS}}$, & $H, L_{O}, T_{*}, u_{*}, \beta$ \\
& $z_{\mathrm{EC}}, G, R_{N}$ & \\
\hline
\end{tabular}

The iterative procedure described in the "classical method" is also applied, but $C_{T^{2}}$ is computed using the latter expression for $\beta$. However, because $\beta$ depends on $H_{\text {LAS }}$, an extra iterative step is required (Fig. 5). The principle advantage of the " $\beta$-closure method" is that no turbulent flux measurements are necessary. Only the net radiation $\left(R_{N}\right)$ and the soil heat flux $(G)$ are required. In most cases, the impact of $S$ is also weak and can thus be neglected. Figure 5 describes the iterative procedure of the BCM. In this case, initial assumptions are needed for the Bowen ratio $\beta$ and the Obukhov length $L_{O}$. First, $C_{T^{2}}$ is calculated using a first guess for $\beta$, and $T_{*}$ and $u_{*}$ are derived from a first guess for $L_{O}$. Subsequently, $L_{O}$ is re-estimated and $H_{\mathrm{LAS}}$ is computed using $T_{*}$ and $u_{*}$, whereas $\beta$ is deduced from the energy balance closure (Eq. 13). When calculated $L_{O}$ values converge, $T_{*}$ and $u_{*}$ are computed to estimate the final value of the sensible heat flux. The iterative procedure is similar to the one used in the classical method, except that $\beta$ is derived from the energy 
balance closure, instead of being derived from the turbulent heat flux measurements $\left(H\right.$ and $\left.L_{v} E\right)$. As the Bowen ratio is determined iteratively, and not by measurement, its associated error (standard deviation) is null.

In order to evaluate the energy balance closure and its impact on the method, a parameter is introduced to characterise the percentage of closure. This parameter was calculated according to EC data, and was designated the energy balance fraction (or Energy Balance Ratio when averaged over a long period of time, Gu et al., 1999):

$\gamma=\frac{H+L_{v} E}{R_{N}-G-S}$

This ratio can be represented by the available energy, which is the ratio of the difference between net radiation and the sum of soil heat flux and heat storage $\left(R_{N}-G-S\right)$, all divided by the turbulent fluxes $\left(H+L_{v} E\right)$. For the three periods considered, the energy balance fraction was equal to $81 \%$, which is quite typical for this type of surface (Fig. 6).

\subsubsection{Uncertainty calculation}

As measurement uncertainties (random and systematic errors) may affect the final estimation of the flux, it is worth comparing both methods in terms of $H_{\text {LAS }}$ uncertainty. Here, to determine the uncertainty of $H_{\mathrm{LAS}}$, a standard deviation $\left(\sigma_{H}\right)$ was calculated for both methods, according to formula for Gaussian Error Propagation (Marx et al., 2008):

$\sigma_{H}^{2}=\sum\left(\frac{\partial H}{\partial \text { Input }_{i}}\right)^{2} \sigma_{\text {Input }_{i}}^{2}+\left(\frac{H_{h i}-H_{d b}}{2}\right)^{2}$

where $\sigma$ is the standard deviation and Input ${ }_{i}$ corresponds to the input variables of Table 1 (for the case of WinLas). The second term corresponds to the uncertainty in the universal function, with $\mathrm{H}_{h i}$ and $\mathrm{H}_{d b}$ corresponding to $H_{\text {LAS }}$ estimated with the different universal functions reported by Hill et al. (1992) and de Bruin et al. (1993), respectively. Marx et al. (2008) provides measurement uncertainties for the parameters in Table 1: $C_{n^{2}}(0.5 \%), T(0.1 \mathrm{~K}), u(0.5 \%), P(100 \mathrm{~Pa})$, $z_{0}(10 \%), z_{\mathrm{LAS}}(0.5 \mathrm{~m}), z_{\mathrm{EC}}(0.1 \mathrm{~m})$. The net radiation uncertainty was close to $5-6 \%$, whereas the error in soil heat conduction measurements $(G)$ was between $15 \%$ and $20 \%$ (Twine et al., 2000, Kohsiek et al. 2007). When attempting to determine $H_{\text {LAS }}$ uncertainty by the " $\beta$-closure method", uncertainties on $R_{N}, G$ and $S$ will be added to Eq. (15), as they intervene in the energy balance closure.

Prior to investigating the influence of the Bowen ratio on $H_{\text {LAS }}$ estimation, a preliminary uncertainty analysis was performed. Assuming that the uncertainty on $\beta$ is null, sensible heat flux values are calculated via the classical method, the uncertainties $\varepsilon$ in the flux estimates for each period (which correspond to the average value of $\sigma_{H} / H_{\mathrm{LAS}}$ over that period) are $\varepsilon=11.3 \%$ in April (LAI maximum), $\varepsilon=11.4 \%$ in June (senescence) and $\varepsilon=12.1 \%$ in September

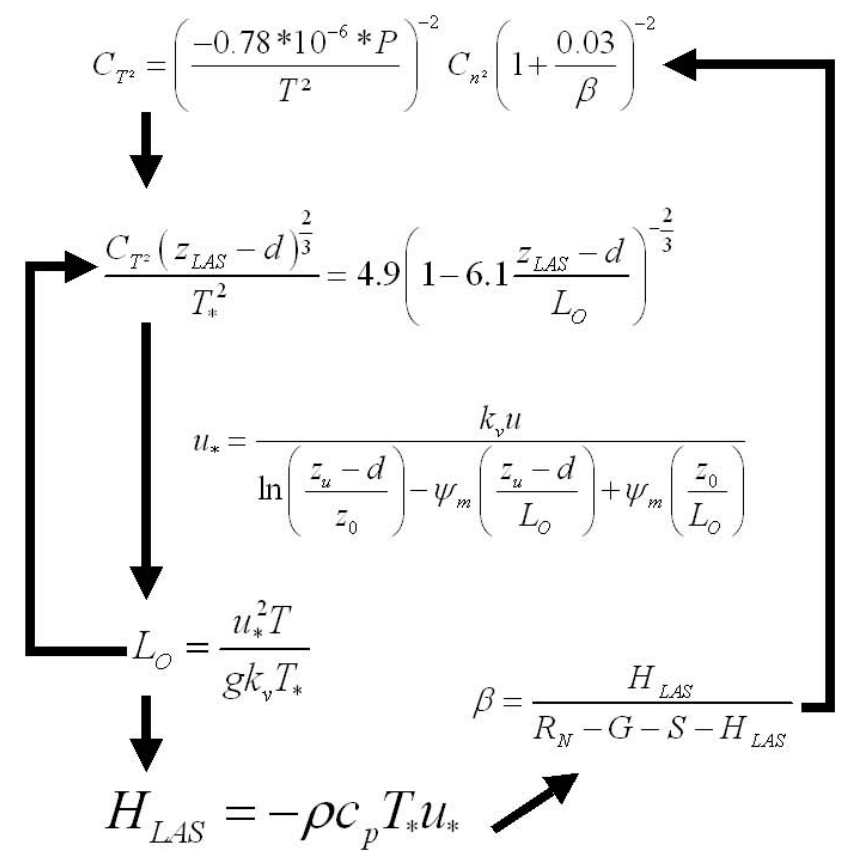

Fig. 5. Schematic description of the " $\beta$-closure method" algorithm.

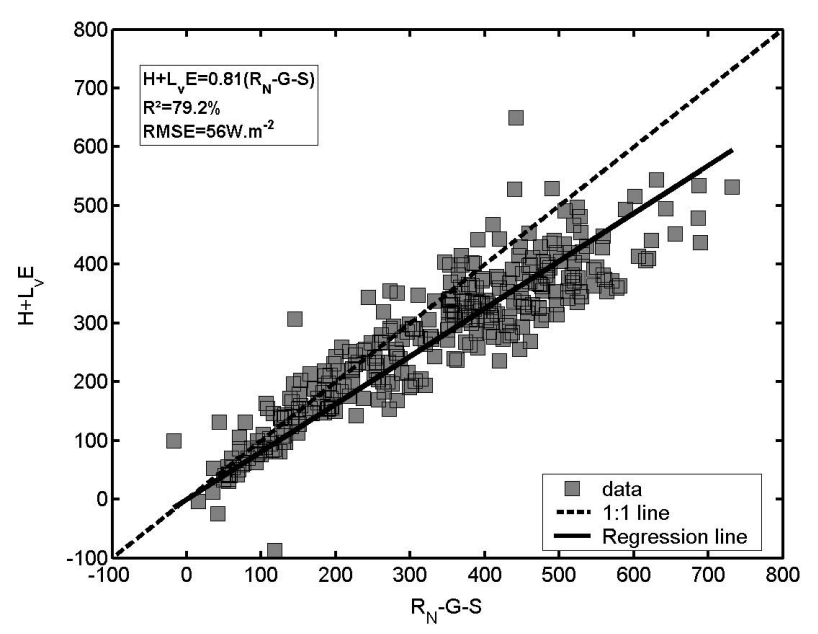

Fig. 6. Turbulent heat fluxes $\left(H+L_{v} E\right)$ versus net radiation minus soil heat conduction and heat stockage $\left(R_{N}-G-S\right)$ for the whole dataset. The best linear fit with a zero-origin is: $H+L_{v}$ $E=0.81\left(R_{N}-G-S\right)$ with a correlation of $R^{2}=0.79$.

(bare soil). The difference between these results and the relative uncertainties of 7 to $8 \%$ found by Marx et al. (2008) can be explained by the height of the scintillometer, which was relatively close to the surface. Uncertainties could be reduced by an estimated 3\% if the instrument height was doubled. In September, uncertainties associated with $z_{\mathrm{EC}}$ and $z_{0}$ tend to increase the uncertainty in $H_{\mathrm{LAS}}$, as these latter parameters become quite small. Specifically, they depend on vegetation height $(d)$, which is itself rather low during that period $\left(h_{\mathrm{veg}}=0.15 \mathrm{~m}\right): d=0.09 \mathrm{~m}$ and $z_{0}=0.015 \mathrm{~m}$. 


\section{Results and discussion}

For the three considered periods of 2007, the Bowen ratio $\beta$ varied between values of 0.02 to 4.86 (Fig. 3). As $\beta$ can have very low values, it is important to quantify its influence both in terms of flux estimates and uncertainty. When a high degree of precision is required for $H_{\text {LAS }}$ flux values and little information is available regarding the Bowen ratio, the " $\beta$ closure method" (BCM) is quite attractive, as no direct measurements of $\beta$ are required. Indeed, it can be very useful for longterm experiments in which measurements of $\beta$ are not accurate, due to a minimum instrumental set-up at the field site. To quantify the impact of $\beta$ on flux calculations, the robustness of the classical and BCM methods was investigated during the year 2007.

\subsection{Sensible heat flux calculated via the classical method}

The Bowen ratio is first calculated with 30 min averaged values of $H_{\mathrm{EC}}$ and $L_{v} E_{\mathrm{EC}}$. Then, $H_{\mathrm{LAS}}$ is estimated via the classical method using these $\beta$ values. Results are displayed for each period (April, June, September 2007) in Fig. 7, comparing scintillometer data versus the corresponding EC fluxes.

It appears that both datasets are well correlated in June $\left(H_{\mathrm{LAS}}=0.98 H_{\mathrm{EC}}, \quad R^{2}=95 \%\right)$ and in September $\quad\left(H_{\mathrm{LAS}}=1.02 H_{\mathrm{EC}}, \quad R^{2}=91 \%\right)$. In April, when fluxes are weaker, the correlation remains satisfying $\left(H_{\mathrm{LAS}}=1.02 H_{\mathrm{EC}} R^{2}=74 \%\right)$.

Uncertainties related to the flux computation were also quantified. For the different periods, a $17.3 \%$ error in $H_{\text {LAS }}$ was obtained in April, $11.7 \%$ in June, and $12.1 \%$ in September. The uncertainties in $H_{\text {LAS }}$ increased as the value of the Bowen ratio decreased. It must be noted that in our case, uncertainty in $\beta$ only considers random errors. If the value $\sigma_{\beta}=0.18$ given by Twine et al. (2000) is used, which combines systematic and random errors, the predicted uncertainty in $H_{\text {LAS }}$ is much higher (48\% in April, $12.6 \%$ in June and $12.2 \%$ in September).

As we noticed formerly, the friction velocity can be either calculated iteratively or measured by the EC system. A comparison has been performed using measurements of the friction velocity (from the EC system) instead of iterative computation for the period P3 as both footprints (of the EC station and scintillometer) are superimposed in this period and $\beta$ sensitivity of $H_{\mathrm{LAS}}$ is negligeable. Then, $H_{\mathrm{LAS}}$ fluxes were calculated with the classical method considering a measured friction velocity. Results show large discrepancies while using $u_{*}$ from EC set-up, whereas $u_{*}$ calculated by iterations computes $H_{\text {LAS }}$ with greater accuracy (Fig. 8 ).

To sum up the results obtained with the classical method, it can be concluded that, for high Bowen ratio, the sensible heat flux derived from scintillometer $H_{\text {LAS }}$ is well correlated with $H_{\mathrm{EC}}\left(R^{2}>0.9\right)$. For low Bowen ratio, this correlation is weaker, due to the strongest sensitivity of $C_{T^{2}}$ to
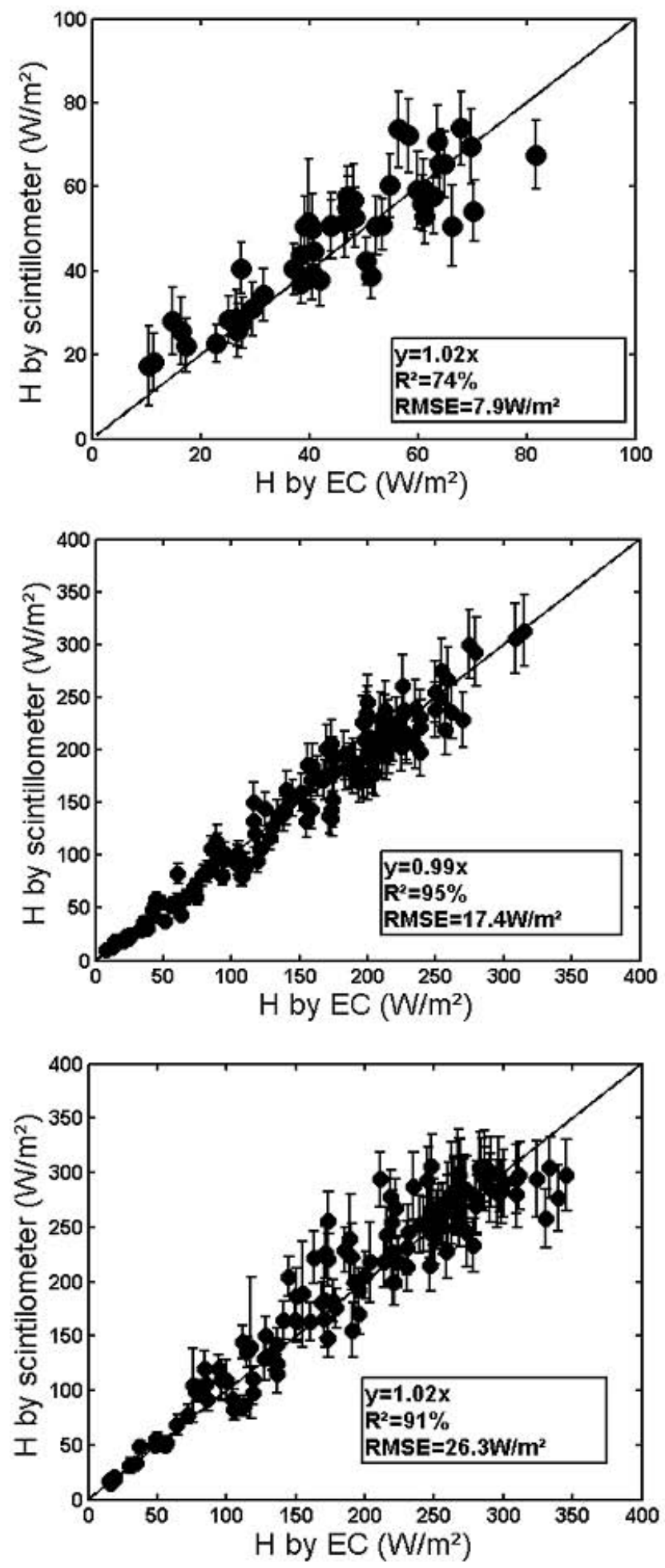

Fig. 7. Comparison between $H_{\mathrm{EC}}$ calculated by Eddy Correlation, and $H_{\mathrm{LAS}}$ derived from scintillometer, and calculated with the classical method, during the three periods: (a) April results (P1), (b) June results (P2) and (c) September ones (P3). 


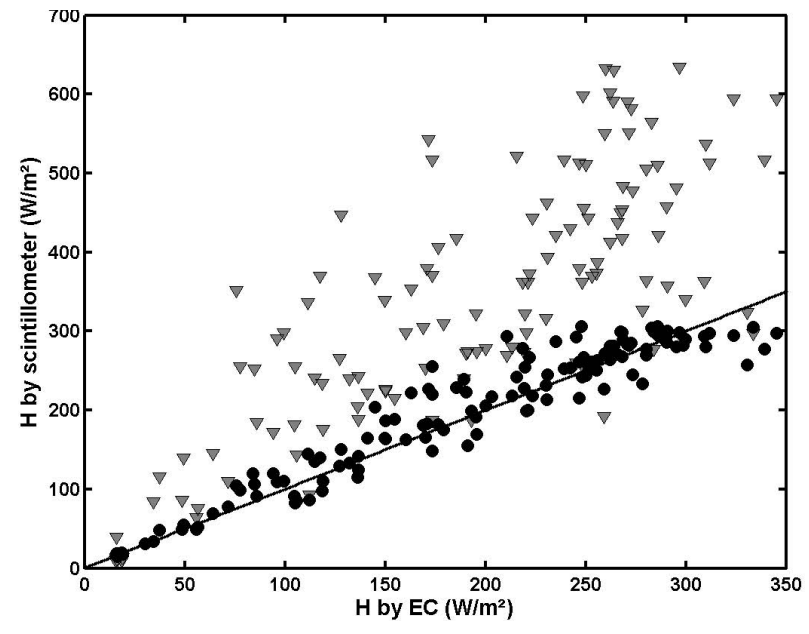

Fig. 8. Comparison between $H_{\mathrm{EC}}\left(H\right.$ by EC) and $H_{\mathrm{LAS}}$ ( $H$ by scintillometer) calculated by the Classical method (black circles) or by the same method using $u_{*}$ calculated by EC set-up (grey triangles) during the period P3. Black line stands for the 1:1 correlation.

the correction term in $\beta$ (Eq. 4) but remains acceptable. Besides, sensible heat fluxes derived from scintillometer measurements suffer from high measurements uncertainties that range from $17 \%$ to $48 \%$ of the flux values. Moreover, as $\beta=H_{\mathrm{EC}} / L_{v} E_{\mathrm{EC}}$, depends on $H_{\mathrm{EC}}$ and that $H_{\mathrm{LAS}}$ is also compared to $H_{\mathrm{EC}}$, the independence of the results can be discussed. Besides, EC set-up are often the only source of information available for turbulent parameters as $\beta$ (Hartogensis et al., 2003; Kohsiek et al., 2006; Von Randow et al., 2008), which imposes to consider slight dependence of $H_{\mathrm{LAS}}$ to $H_{\mathrm{EC}}$.

\subsection{Sensible heat flux values calculated via the " $\beta$ - closure method" (BCM), balance fraction and Bowen ratio influence}

The requirement of $\beta$ values calculated every $30 \mathrm{~min}$ to minimise measurement uncertainties could limit the use of scintillometry in wet conditions when the Bowen ratio is small. For instance, such conditions were encountered over the Amazonian forest by Da Rocha et al. (2003), who estimated a mean annual Bowen ratio $\beta$ of 0.17 , or by Sadhuram et al. (2001), who found that $\beta$ can be even smaller than 0.1 during monsoon periods or over open ocean waters. In our experimental site, $38 \%$ of the days in 2007 corresponded to a Bowen ratio smaller than 0.4. Using an alternative computation method that does not include a measurement of $\beta$ could thus extend the field of application of scintillometry. To this end, the accuracy and robustness of the " $\beta$-closure method" (BCM) were examined.

Hoedjes et al. (2002) applied this method to derive fluxes using scintillometry over an irrigated area in Mexico. Their measurements showed good correlations with EC results, and
Table 2. Correlation $\left(R^{2}\right)$ and linear fit between $H_{\text {LAS }}$ estimated with the scintillometer according to both methods (the classical one and the $\mathrm{BCM}$ ) and $H_{\mathrm{EC}}$ measured with ECstation.

\begin{tabular}{lcccc}
\hline & Classical Method & BCM & $\gamma$ & $\beta$ \\
\hline April & $1.02 \times\left(R^{2}=74 \%\right)$ & $0.95 \times\left(R^{2}=57 \%\right)$ & $78.5 \%$ & 0.12 \\
June & $0.99 \times\left(R^{2}=95 \%\right)$ & $\left.0.96 \times R^{2}=94 \%\right)$ & $79.7 \%$ & 1.01 \\
September & $1.02 \times\left(R^{2}=91 \%\right)$ & $1.01 \times\left(R^{2}=91 \%\right)$ & $98.7 \%$ & 2.8 \\
\hline
\end{tabular}

displayed a tendency to overestimate the sensible heat flux in dry conditions. In the current study, the sensible heat flux was calculated similarly for the three selected periods. The influence of the two main parameters, the energy balance fraction $(\gamma)$, and the Bowen ratio, was also analysed. The results for the three periods are presented in Table 2. In April, $\beta$ is very small $(0.12)$ and the energy budget is poorly closed $(\gamma=78.5 \%)$. In June, the energy balance fraction is still small $(\gamma=79.7 \%)$ but the Bowen ratio increases $(\beta \approx 1)$. In September, the energy balance is almost closed $(\gamma=98.7 \%)$, and $\beta$ is high.

Performances of scintillometers to estimate $H$ flux have already been studied in the case of homogeneous surface and showed high correlation with $H_{\mathrm{EC}}$ (McAneney et al., 1995; De Bruin et al., 1995; Hoedjes et al., 2002). Then, the discussion is focused on the comparison of both methods.

In a preliminary analysis, it can be observed that the " $\beta$ closure method" tended to give the same results as, classical method, especially during the June and September periods (Fig. 9). However, $\gamma$ and $\beta$ seemed to affect the results of the " $\beta$-closure method" : $H_{\text {LAS }}$ by BCM diverges from $H_{\text {LAS }}$ by Classical method, when both parameters decreased. The influence of $\beta$ on this divergence is more stringent, as shown by the comparison of the April and June results (where $\gamma$ is approximately the same). It is evident that the decrease in $\beta$ was followed by an underestimation of $H_{\text {LAS }}$ by $6 \%$ in April, $3 \%$ in June and $1 \%$ in September. It can be noted that including the storage term $(S)$ in the energy budget modified the final $H_{\text {LAS }}$ estimates by less than $1 \%$. Thus, this term can be neglected while using the " $\beta$-closure method" without significant error.

According to Gaussian Error Propagation calculations, and with assumed uncertainties of $6 \%$ for $R_{N}$ and $20 \%$ for $(G+S)$, averaged uncertainties for the different periods were reduced to $18.4 \%$ in April, $12.8 \%$ in June, and $13.1 \%$ in September. The contribution of the error in $R_{N}$ and $(G+S)$ values on the final $H_{\text {LAS }}$ uncertainty was approximately $1 \%$.

In April, although the determination of the sensible heat flux with a scintillometer was more sensitive than during the other selected periods, good results were obtained with reasonable uncertainties (Fig. 9). Furthermore, the BCM computation was less sensitive to measurement uncertainties under low $\beta$ conditions, a finding that is very promising for the use of BCM in very wet regions. 


\subsection{Moisture influence}

Further analysis has been performed to include the moisture effect $\left(R_{T q}\right)$ in $H_{\text {LAS }}$ computation with both methods. Moene (2003) estimated the possible error due to the approximation of $\left|R_{T Q}\right|=1$ in Eq. (4), to be up to $40 \%$ when the Bowen ratio is low, and advised to neglect the correction term in $\beta$. Furthermore, Lüdi et al. (2008) showed that $R_{T Q}$ is dependent upon the Bowen ratio. The lowest the Bowen ratio is, the worst the temperature and humidity are correlated. Then, according to this criteria the period P1 is the most sensitive period to $R_{T Q}$ fluctuations and needs to be further investigated to quantify the influence of the lack of correlation between temperature and humidity. Besides the influence of $R_{T q}$ is negligeable in June and September (Moene, 2003).

$R_{T Q}$ has been calculated for the three periods, at the time scale of $30 \mathrm{~min}$. The averages values of $R_{T Q}$ for each period is 0.76 for $\mathrm{P} 1,0.66$ for $\mathrm{P} 2$, and 0.59 for $\mathrm{P} 3$, which are comparable with other authors. For instance, Sorbjan (1993) sums up the results of different experimentations and conclude that $R_{T Q}$ is between 0.6 and 0.8 in the surface boundary layer.

The sensible heat flux has been calculated with experimental values of $R_{T Q}$, and was then compared to previous results (where $\left|R_{T Q}\right|=1$ is assumed) for the period P1 (Fig. 10). The results show a relative underestimation of $H_{\text {LAS }}$ in April due to the approximation of $R_{T Q}=1$ of $6 \%( \pm 3 \%)$ with the Classical method and $9 \%( \pm 4 \%)$ with the BCM.

\section{Conclusions}

Measurements of the mass and energy exchanges between the surface and the atmosphere at the ecosystem scale are a major topic of many projects involved in land-surface monitoring (e.g., Sud Ouest project). Whereas Eddy Covariance (EC) stations provide local measurements, scintillometers are able to estimate the sensible heat flux from measurements of the structure parameter of refractive index, $C_{n^{2}}$, integrated over distances up to several kilometres. However, their accuracy relies on the accuracy of the meteorological parameters required for calculating the sensible heat flux. Among these parameters, we focused on the Bowen ratio, $\beta$, which is the most sensitive to uncertainty in meteorological measurements, since it relies on the measurement of the turbulent fluxes $H$ and $L_{v} E$ by standard EC systems. With the objective of installing scintillometers as autonomous devices, there is a strong incentive to further investigate the dependence of the heat fluxes measured by these devices upon input values for $\beta$. Therefore, two different computation methods of the sensible heat flux were tested to evaluate the requirements for installing scintillometers in tandem with additional measurement devices in order to achieve a desired degree of accuracy. a)

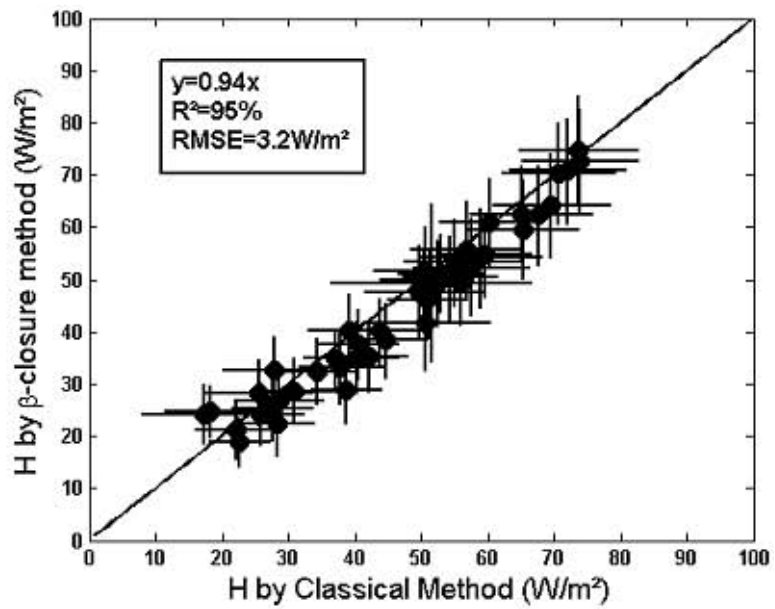

b)

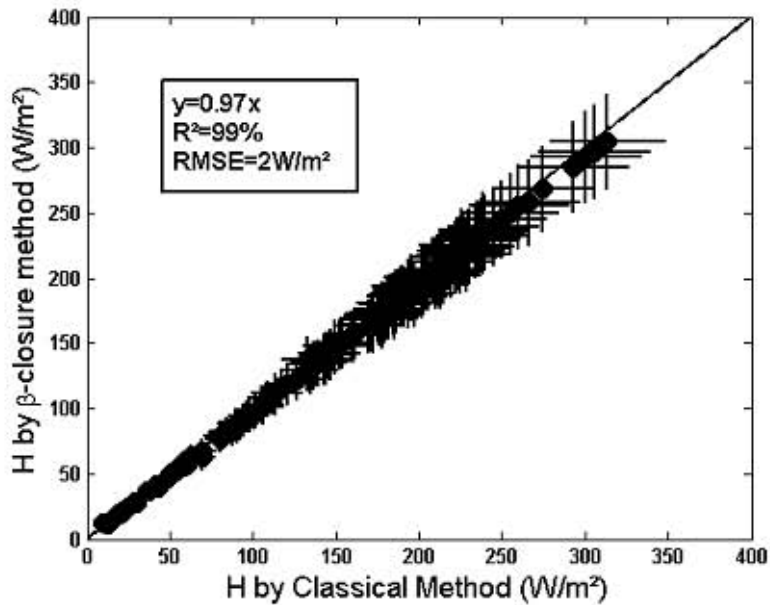

c)

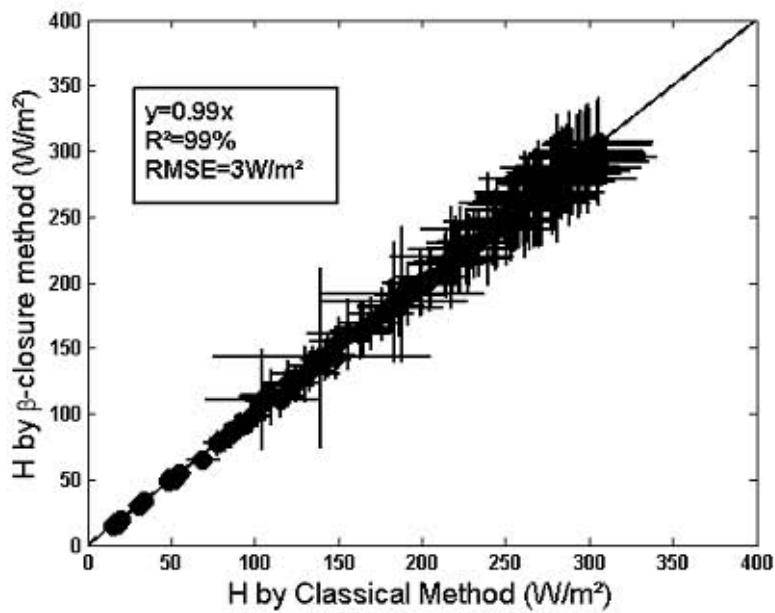

Fig. 9. Comparison of the sensible heat fluxes derived from the scintillometer $H_{\text {LAS }}$ with the " $\beta$-closure method" (BCM) versus the one derived with the classical method: (a) April results, (b) June results and (c) September ones. 


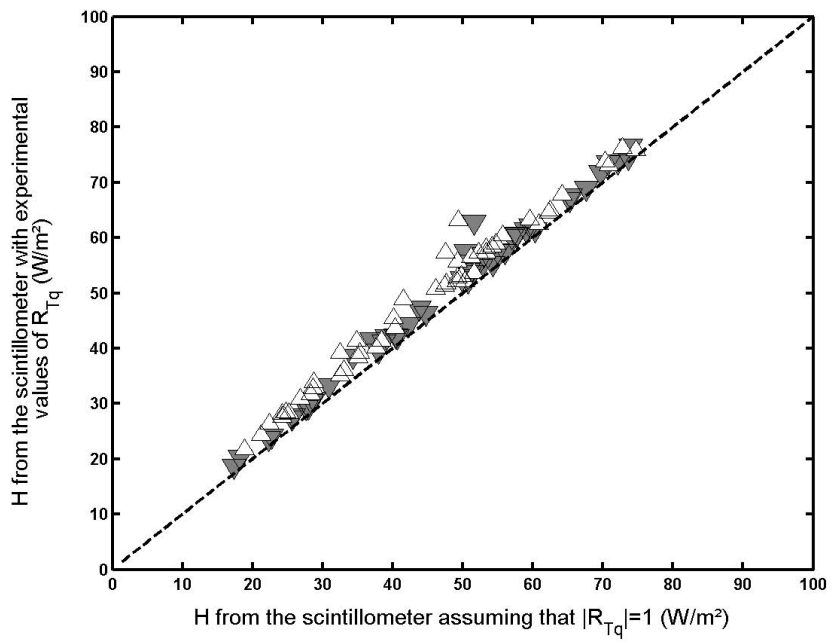

Fig. 10. Comparison between $H$ calculated with the scintillometer considering a perfect temperature/humidity cross-correlation $\left(R_{T Q}=1\right)$, and with the measured one, for the period P1. Classical method is represented by grey triangles, and BCM by white triangles.

The influence of a measured Bowen ratio on flux calculations was first studied via a "classical method" (WINLAS software) for three different periods of vegetation growth (April, June and September 2007). The sensible heat flux $H$ was calculated with 30 min-averaged values of $\beta$ measured using an EC flux system. In June and September, when $\beta>1$, $H_{\mathrm{LAS}}$ and $H_{\mathrm{EC}}$ are well correlated, and the uncertainty on $H_{\text {LAS }}$ measurement is around $12 \%$. In April 2007, when the Bowen ratio was smallest $(\beta=0.12)$, the correlation between $H_{\text {LAS }}$ and $H_{\text {EC }}$ decreases $(71 \%)$ due to the strongest sensitivity of $H_{\mathrm{LAS}}$ to the correction term in $\beta$. Moreover, the lack of accuracy on $\beta$ measurement for low $\beta$ values produced an increase in the measurement uncertainty (between 17 and 48\%).

The " $\beta$-closure method" is a useful alternative when information about the Bowen ratio is unavailable. In this case, the computational algorithm only requires net radiation and soil conductivity measurements to determine the Bowen ratio, assuming that the energy balance is closed. With this method, the results are rather satisfying even in April, considering the small under-estimation of $H_{\text {LAS }}(<6 \%)$ even when the Bowen ratio was small. Furthermore, the uncertainty in $H_{\text {LAS }}$ was limited to $18.5 \%$ in April, and $13 \%$ in June and September. These findings suggest that at low Bowen ratios, fluxes can be estimated with accuracy and with less uncertainty using the BCM than with classical methods. In addition, the BCM requires less instrumentation for turbulent measurements.

The approximation of a perfect correlation between temperature and humidity $\left(R_{T Q}=1\right)$ has been discussed in low Bowen ratio conditions (April) which is the most sensitive case to $R_{T Q}$ fluctuations. $R_{T Q}$ values have been integrated over $30 \mathrm{~min}$ and included into each computational method. It results in a relative underestimation of $H_{\mathrm{LAS}}$, using $\left|R_{T Q}\right|=1$, between 6 and $9 \%$ in comparison with $H_{\text {LAS }}$, using experimental values of $R_{T Q}$.

When using a scintillometer as an autonomous device, it is advisable to employ the " $\beta$-closure method", as one can reduce the uncertainties in flux estimates caused by the lack of accuracy in the estimation of $\beta$, and by the systematic and random errors in measurements. An interesting perspective might be to test this calculation method under very wet conditions (such as measurement campaigns over lakes or open ocean), in which EC station installation is difficult.

Acknowledgements. The SudOuest experiment was supported by the Conseil Régional Midi-Pyrénées, the CNES (Centre National d'Etudes Spatiales), and the Ministère de l'Environnement (GICC). It was also partly funded by the CarboEurope-IP program and CNRS/INSU. The authors would like to thank l'Ecole Supérieure d'Agriculture de Purpan and the congregation of Notre Dame de la Motte for welcoming us at the Lamasquère site. We would like to express our gratitude to all of the technical teams (Hervé Gibrin, Bernard Marciel). Finally, we are also very grateful to W. Koshiek for his helpful suggestions on the development of our scintillometer and to A. Moene for his help and comments regarding uncertainty calculations.

Edited by: G. Ehret

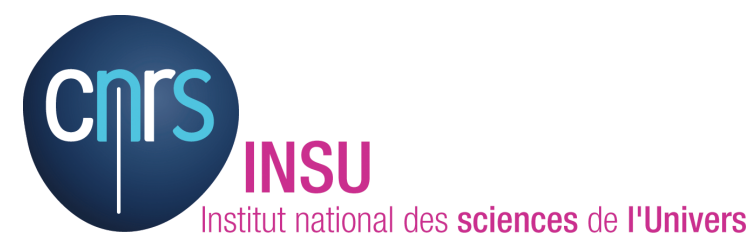

The publication of this article is financed by CNRS-INSU.

\section{References}

Andreas, E. L.: Estimating $\mathrm{Cn}^{2}$ over Snow and Sea Ice from Meteorological Data, J. Opt. Soc. Am., 5, 481-495, 1988.

Andreas, E.L.: Two-wavelength method of measuring pathaveraged turbulent surface heat fluxes, J. Atmos. And Ocean Tech., 6, 280-292, 1989.

Asanuma, J. and Lemoto, K.: Measurements of regional sensible heat flux over Mongolian grassland using large aperture scintillometer, J. Hydrol., 333, 58-67, 2007.

Aubinet, M., Grelle, A., Ibrom, A., Rannik, Ü., Moncrieff, J., Foken, T., Kowalski, A. S., Martin, P. H., Berbigier, P., Bernhofer C., Clement, R., Elbers, J., Granier, A., Grünwald, T., Morgenstern, K., Pilegaard, K., Rebmann, C., Snijders, W., Valentini, R., and Vesala, T.: Estimates of the annual net carbon and water exchange of forests: The EUROFLUX methodology, Adv. Ecol. Res., 30, 113-175, 2000.

Aubinet, M., Clement, R., Elbers, J., Foken, T., Grelle, A., Ibrom, A., Moncrieff, H., Pi-legaard, K., Rannik, U., and Rebmann, C. : Methodology for data acquisition, storage and treatment, in: 
Fluxes of carbon, water and energy of European forests. Ecological Studies, edited by: Valentini, R., 163, Springer, Berlin, Heidelberg, 9-35, 2003.

Bastiaanssen, W. G. M., Menenti, M., Feddes, R. A., and Holtslag, A. A. M.: A Remote Sensing Surface Energy Balance Algorithm for Land (SEBAL) - 1. Formulation, J. Hydrol., 212-213, 198212, 1998.

Billesbach, D. P., Fischer, M. L., Torn , M. S., and Berry, J. A.: A portable eddy covariance system for the measurement of Ecosystem-Atmosphere exchange of $\mathrm{CO}_{2}$, Water Vapor, and Energy, J. Atmos. Oceanic. Technol., 21, 684-695, 2004.

Bowen, I. S.: The ratio of heat losses by conduction and by evaporation from any water surface, Phys. Rev., 27, 779-787, 1926.

Brotzge, J. A.: Closures of the surface energy budget, PhD Thesis, The Univeristy of Oklahoma, March 2001, 208 pp., 2001.

Businger, J. A., Miyake, M., Dyer, A. J., and Bradley, E. F.: On the direct determination of heat flux near the ground, J. Appl. Meteor., 6, 1025-1031, 1967.

Dabberdt, W. F., Lenschow, D. H., Horst, T. W., Zimmerman, P. R., Oncley, S. P. and Delany, A. C.: Atmosphere-surface exchange measurements, Science, 260, 1472-1481, 1993.

Da Rocha, H.R., Goulden, M. L., Miller, S. D., Menton M. C., Pinto, L. D. V. O., de Freitas, H. C., and Silva Figueira, A. M.: Seasonality of water and heat fluxes over a tropical forest in eastern amazonia, Ecol. Appl., 14, No. sp4, 22-32, 2004.

De Bruin, H. A. R, Kohsiek,W., van den Hurk, B. J. M.: A verification of some methods to determine the fluxes of momentum, sensible heat, and water vapor using standard deviation and structure parameter of scalar meteorological quantities, Bound.-Lay. Meteorol., 63, 231-257, 1993.

De Bruin, H. A. R., Van den Hurk, B. J. J. M., and Kohsiek, W.: Ths Scintillation Method tested over a dry vineyard area, Bound.Lay. Meteorol., 76, 25-40, 1995.

Dugas, W. A., Fritschen, L. J., Gay, L. W., Held, A. A., Matthias, A. D., Reicosky, D. C., Steduto, P. and Steiner, J. L.: Bowen ratio, eddy correlation, and portable chamber measurements of sensible and latent heat flux over irrigated spring wheat, Agric. For. Meteorol., 56, 1-20, 1991.

Foken, T.: The energy balance closure problem - An overview, Ecol. Appl., 18, 1351-1367, 2008.

Green, A. E. and Ayashi, Y.: Using the scintillometer over a rice paddy, Japan, J. Agric. Meteorol., 54, 225-231, 1998.

Gu, J., Smith, E. A., and Merritt, J. D.: Testing Energy Balance Closure with GOES retrieved Net Radiation and in Situ Measured Eddy Correlation Fluxes in BOREAS, J. Geophys. Res., 104, 27-81, 1999.

Halldin, S. and Lindroth, A.: Errors in net radiometry: comparison and evaluation of six radiometer designs, J. Atmos. Oceanic. Technol., 9, 762-783, 1992.

Hartogensis, O. K., Watts, C. J., Rodriguez, J.-C., de Bruin, H. A. R.: Derivation of the effective height for scintillometers: La Poza experiment in Northwest Mexico, J. Hydrol., 4, 915-928, 2003.

Hill, R. J., Clifford, S. F. and Lawrence, R. S.: Refractive index and absorption fluctuations in the infrared caused by temperature, humidity and pressure fluctuations, J. Opt. Soc. Am., 70, 1192-1205, 1980.

Hill, R. J.: Implications of Monin-Obukhov Similarity Theory for Scalar Quantities, J. of Atm. Sci., 46, No.14, 1989.

Hill, R. J., Ochs, G. R., and Wilson, J. J.: Measuring Surface
Layer Fluxes of Heat and Momentum Using Optical Scintillation, Boundary-Layer Meteorol., 58, 391-408, 1992.

Hoedjes, J. C. B., Zuurbier, R. M. and Watts, J. C.: Large aperture scintillometer used over a homogeneous irrigated area, partly affected by advection, Bound.-Lay. Meteorol., 105, 99-117, 2002.

Hoedjes, J. C. B., Chehbouni, A., Ezzahar, J., Escadafal, R., and De Bruin, H. A. R.: Comparison of Large Aperture Scintillometer and Eddy Covariance Measurements: Can Thermal Infrared Data be Used to Capture Footprint Induced Differences?, J. Hydrometeorol., 8 (2), 144-159, 2007.

Horst, T. W. and Weil, J. C.: How far is far enough? The fetch requirements for micrometeorological measurement of surface fluxes, J. Atm. Oc. Tech., 11, 1018-1025, 1994.

Kleissl, J., Gomez, J., Hong, S.-H., Hendrickx, J. M. H, Rahn, T., and Defoor, W. L.: Large Aperture Scintillometer Intercomparison Study, Bound.-Lay. Meteorol., 128, 133-150, 2008.

Kohsiek, W., Meijninger, W. M. L., deBrui, H. A. R., and Beyrich, F.: Saturation of the large aperture scintillometer, Boundary-Lay. Meteorol., 121, 111-126, 2006.

Kohsiek, W., Liebethal, C., Foken, T., Vogt, R., Oncley, S. P., Bernhofer, C., de Bruin, H. A. R.: The energy balance experiment EBEX-2000, Part III : Behaviour and quality of radiation measurements, Boundary-Lay. Meteorol., 123, 55-75, 2007.

Konzelmann, T., Calanca, P., Muller, G., Menzel, L., and Lang, H.: Energy balance and evapotranspiration in a high mountain area during summer, J. Appl. Meteorol., 36, 7, 966-973, 1997.

Lamaud, E., Ogée, J., Brunet, Y., and Berbigier, P.: Validation of Eddy flux measurements above the Understorey of a Pine Forest, Agr. Forest. Meteorol., 106, 187-203, 2001.

Lee, X., Massman, W. J., and Law, B.: Handbook of Micrometeorology: A Guide for Surface Flux Measurement and Analysis, Kluwer, Dordrecht, The Netherlands, 250 pp., 2004.

Marx, A., Kunstmann, H., Schuttemeyer, D. and Moene, A. F.: Uncertainty analysis for satellite derived sensible heat fluxes and scintillometer measurements over Savannah environment and comparison to mesoscale meteorological simulation results, Agr. Forest. Meteorol., 148, 656-667, 2008.

McAneney, K. J., Green, A. E., and Astill, M. S.: Large-Aperture scintillometry: the homogeneous case, Agric. For. Meteorol., 76, 149-162, 1995.

Meijninger, W. M. L. and de Bruin, H. A. R.: The sensible heat fluxes over irrigated ares in western Turkey determined with a large aperture scintillometer, J. Hydrol., 229, 42-49, 2000.

Meijninger, W. M. L., Hartogensis, O. K., Kohsiek, W., Hoedjes, J. C. B., Zuurbier, R. M., and De Bruin, H. A. R.: Determination of Area-Averaged Sensible Heat Fluxes with a LargeAperture Scintillometer over a Heterogeneous Surface - Flevoland Field Experiment, Bound.-Lay. Meteorol., 105, 37-62, 2002a.

Meijninger, W. M. L., Green, A. E., Hartogensis, O. K., Kohsiek, W., Hoedjes, J. C. B., Zuurbier, R. M. and De Bruin, H. A. R.: Determination of area-averaged water vapour fluxes with large aperture and radio wave scintillometers over heterogeneous surface-Flevoland field experiment, Bound.-Lay. Meteorol., 105, 63-83, 2002b.

Meijninger, W. M. L., Beyrich, F., Kohsiek, W., Bruin, H. A. R., and de Lüdi, A.: Scintillometer fluxes of sensible and latent heat over a heterogeneous area - a contribution to LITFASS-2003, 16th Symposium on Boundary Layers and Turbulence, 9-13 August 2004, Portland, Maine, Boston, USA: American Meteorological 
Society, 9.2, 2004.

Moene, A. F.: Effects of water vapour on the structure parameter of the refractive index for near-infrared radiation, Boundary-Layer Meteorol., 107, 635-653, 2003.

Nie, D., Kanemasu, E. T., Fritschen, L. J., Weaver, H. L., Smith, E. A., Verma, S. B., Field, R. T., Kustas, W. P., and Stewart, J. B.: An intercomparison of surface energy flux measurement systems used during FIFE 1987, J. Geophys. Res., 97, 1871518724, 1992.

Ochs, G. R. and Wilson, J. J.: A second-Generation Large-Aperture Scintillometer, NOAA Tech. Memo., ERL WPL-232, Env. Res. Lab, Boulder, CO, 24 pp., 1993.

Panofsky, H. A and Dutton, J. A.: Atmospherric Turbulence: Models and Methods for Engineering Applications, J. Wiley, New York, USA, 397 pp., 1984.

Paulson, C. A. : The mathematical representation of wind speed and temperature profiles in the unstable atmospheric surface layer, J. Appl. Meteorol., 9, 857-861, 1970.

Sadhuram Y., Ramana Murthy, T. V., Sarma, Y. V. B., and Murthy, V. S. N.: Comments on On the estimation of overwater Bowen ratio from sea - air temperature difference., J. Phys. Oceanogr., 31, 1933-1934, 2001.

Sorbjan, Z.: Notes and Correspondaence : Monin-Obukhov Similarity for Refractive Index Revisited, J. Atmos. Sci., 50, 21, 3677-3679, 1993.
Twine, T. E., Kustas, W. P., Norman, J. M., Cook, D. R, Houser, P. R., Meyers, T. P., Prueger, J. H., Starks, P. J. and Wesely, M. L.: Correcting Eddy-Covariance Flux Underestimates over a Grassland, Agr. Forest. Meteorol., 103, 279-300, 2000.

Von Randow, C., Kruijt, B., Holtslag, A. A. M., de Oliveira, M. B. L.: Exploring eddy-covariance and large-aperture scintillometer measurements in an Amazonian rain forest, Agr. Forest. Meteorol., 148, 680-690, 2008.

Wang, T., Ochs, G., and Clifford, S.: Saturation-Resistant optical scintillometer to measure $\mathrm{Cn}^{2}$, J. Opt. Soc. Am., 68, 334-338, 1978.

Webb, E. K. Pearman, G. I., and Leuning, R.: Correction of flux measurements for density effects due to heat and water vapor transfer, Q. J. Roy. Meteor. Soc., 106, 85-100, 1980.

Wesely, M. L.: The combined effect of Temperature and humidity Fluctuations on Refractive index, J. Appl. Meteorol., 15, 43-49, 1976.

Wyngaard, J. C., Izumi, Y., and Collins Jr., S. A.: Behavior of the Refractive Index Structure Parameter near the Ground, J. Opt. Soc. Amer., 61, 1646-1650, 1971. 